\title{
Deniz Taktik İşaretlerinin Yazılı İlk Kaynă̆ı
}

\author{
The First Written Resource of \\ Naval Tactical Signals
}

\author{
Derya Şerif YARKIN* - Gökhan ATMACA**
}

$\ddot{O}_{z}$

Bir savaşta veya çatışmada etkin, hızlı ve güvenilir iletişimin katkısı büyüktür. Deniz savaşlarında uygulanacak iletişimin temelini, kullanilacak taktikler belirler. Deniz savaş biçimlerinde ve araçlarında yaşanan tarihsel süreç dikkate alındiğında, amiraller ve kaptanlar arasındaki iletişimin önemi her zaman yüksek olduğundan, etkin çözüm için sürekli yeni arayışlar içinde olunmuştur. Bugüne değin araştırılmış/bilinen arşiv bilgileri ışığında, Kaptan James Dolfin tarafindan 9 Eylül 1365 tarihinde Venedik filosu için yayınlanmış olan savaş talimatı, bu konuda bir ilktir ve günümüzdeki uygulamaların da atası olmuştur. Latince dilinde ve Venedik lehçesinde hazırlanmış olan bu talimat, zaman içinde önce Italyancaya, daha sonra da Ingilizceye çevrilmiştir. Söz konusu direktifin içeriğinde kullanılan gemici dili dikkate alındığında, çevirilerinin deniz subaylart tarafindan yapılmış olması önemlidir; böylece bilginin güvenilirliği de artmıştır. Bu çalı̧̧ma, Türk Deniz Kuvvetleri'nde görevli taktisyen ve planlayıcılara konuyla ilgili tarihsel bilgi sunmak amactyla yapılmıştır.

Anahtar Kelimeler: Taktik, İletişim, Kadırga, Gemici Dili, Deniz Tarihi.

"(E) Dz. Alb., ORCID: 0000-0003-2060-6301, e-posta: dsyarkin@gmail.com.

** Öğ. Yb., Deniz Müzesi, e-posta: gokhanatmaca@ gmail.com.

Geliş Tarihi/Arrived: 24.02.2019

Kabul Tarihi/Accepted: 09.08.2019 
548

Güvenlik Stratejileri

Cilt: 15

Sayı: 31

Abstract

Effective, fast, and reliable communication provides a great contribution in a battle or conflict. The tactics used in naval wars determine the basis of communication. Considering the historical process in forms and vehicles of the naval wars, the importance of the communication between the admirals and the captains has always been high, so there has always been a new search for effective solution. From the researched/known archive information point of view, the war instruction issued by Captain James Dolfin for the Venetian fleet on September 9, 1365 was a first in this regard and was the ancestor of today's practices. This instruction, which was prepared in Latin and in the Venetian dialect, was first translated into Italian and later into English. Considering the maritime language used in the content of this directive, it is important that the translations were made by naval officers, thus increasing the reliability of the information. This study was carried out in order to present historical information on the related subject to the tacticians and planners in Turkish Naval Forces.

Keywords: Tactics, Communications, Galley, Maritime Language, Naval History.

\section{Giriş}

Dünya yüzeyinin 3/4'ünü kapsayan denizler doğal olarak insanoğlunun ilgi alanına girmiş ve günümüze değin buradaki yerini, önemi artarak koruyabilmiştir. Deniz ortamı insanların öncelikle beslenme, ulaşım, ticaret isteklerinin karşılanması amacıyla kullanılmış, aynı zamanda çıkarlarının da çatıştığı alanlar olmuştur. Deniz alanlarındaki çıkarların korunması ve istila hareketlerinde denizler, acımasızca savaş alanı olarakta kullanılmıştır. Bu nedenle "Deniz Tarihi" denildiğinde ilk akla gelen savaş olmuştur. Denizdeki çatışmalarda ve savaşlarda öne sürülen birliklerin konuşlandırılması, yönlendirilmesi ve değişen koşullara uygun hareketlerle karşıllk verilebilmesi için önceden tasarlanmış hareketlere ve bu hareketleri açıklayacak iletişim araç ve yöntemlerine ihtiyaç duyulur. Bu nedenle, bir savaşta veya çatışmada etkin, hızlı ve güvenilir iletişimin katkısı 
büyüktür. Söz konusu iletişimin sağlanabilmesi için kullanılacak araçlar kadar kullanım amacı da çok önemlidir. Diğer bir deyişle, iletişimde kullanım amacı ne denli daraltılabilirse, hız ve güvenlik o denli arttırılabilir. Dolayısıyla, iletişimi tasarlamadan önce, iletilecek bilgilerin türü ve içeriğinin belirlenmesi gerekir. Bu noktadan yola çıkarak, deniz savaşlarında yararlanılacak iletişimin temelini kullanılacak taktikler belirler demek yanlış olmayacaktır. Denizdeki bir savaş gücüne komuta eden amiral, fazla ayrıntıya girmeden, söz konusu birliğin konuşlanması ve içinde bulunulan duruma en uygun muharebe düzenini uygulaması için genel emirleri vermek, kullanılacak taktikleri emretmek ve gelişen durumun taktik resmini belirlemek (raporlaşma) amacıyla iletişime gerek duymuştur.

Bu çalışma kapsamında, Türkçe çevirisi yapılarak Ek’te sunulan, Kaptan ${ }^{1}$ James Dolfin tarafindan, (o sirada) Kibris'ta bulunan ve dört kadırgadan oluşan bir Venedik Filosu için Latince dili ve Venedik lehçesinde hazırlanmış olan direktif, ${ }^{2}$ günümüze değin elde edilmiş/bilinen ilk ve tek yazılı belgedir. Bu tarihi belge, ilk kez İtalyan Tuğamiral Luigi Fincati ${ }^{3}$ tarafindan 1897 y1lında İtalyanca'ya; ABD'li Tuğamiral Stephen Bleecker Luce ${ }^{4}$ tarafindan da İngilizce'ye çevrilmiştir ${ }^{5}$. Söz konusu direktifin içeriğinde kullanılan gemici dili

${ }^{1}$ Belgenin içeriğinde sıfat olarak "Signore (Bay)" kullanılmıştır.

${ }^{2}$ Pek çok açıdan değerli olan özgün belge, Venedik'te, “Archivis Notarile of Venice"in "Acts"leri arasındaki "Boninsigna Giovanni I.4"de bulunmaktadır.

${ }^{3}$ Tuğamiral Luigi Fincati (1818-1893); Avusturya-Venedik donanmasındaki görevini, Amiral olduktan kısa süre sonra, 1848 Venedik Devrimi öncesinde bırakmıştır. Venedik Parlamentosunda milletvekilliği de yapmıştır. 1882 yılında yeniden göreve çağırılarak Kraliyet Deniz Akademisi komutanı olmuştur. Mesafe bulucunun (telemetre) mucididir.

${ }^{4}$ Tuğamiral Stephen Bleecker Luce (1827-1917); 14 yaşında donanmaya katılmış, Amerikan İç Savaşı sırasında ilk buharlı (yandan çarklı) savaş gemilerine komutanlık yapmıştır. Deniz stratejisi ve eğitim konularında uzmandır. ABD Deniz Harp Akademisi'nin kurucusu (1884) ve ilk Başkanıdır.

5 "Orders and Signals of the Venetian Fleet Commanded by Mr. James Dolfin, A.D. 1365", The Proceedings, Vol. XX, No: 3, Whole No. 71, U.S. Naval Institute, Annapolis MD, 1894, s. 545-550. 
Güvenlik

Stratejileri

Cilt: 15

Say1: 31

dikkate alındığında, çevirilerinin deniz subayları tarafından yapılmış olması da önemlidir, böylece bilginin güvenilirliği de artmıştır.

\section{Deniz Savaşları Tarihinde Deniz Savaşı Yöntemlerinin ve Savaş Gemilerinin Gelişimi}

Dünya deniz savaşları tarihine kısaca göz atılacak olursa, Haçlı Seferlerinin, donanmaların gelişimleri üzerinde etkin rol oynadığı görülür. Akdeniz'de, yüzlerce, hatta binlerce kadırga ${ }^{6}$, bu amaçla oluşturulan dev donanmalarda görev almış; yüzbinlerce gemici ${ }^{7}$ bu sularda savaşmış ve sonuçta ya ölmüş ya da kaybolmuştur. Yaklaşık 1350 yılına kadar geçen sürede gerek kürek, gerekse onu izleyen yelken döneminde deniz savaşları, kara savaşlarına çok benzer biçimde uygulanıyordu. $\mathrm{Bu}$ deniz savaşlarında gemiler, bir grup halinde düşmana saldırıyor, yeterince yaklaşıldığında uçları yakılmış veya yalnızca sivriltilmiş oklar firlatılıyor, daha da yaklaşıldığında özel olarak yapılmış aygıtlarla taşlar atılıyor ve/veya Rum Ateşi adı verilen öldürücü sıvı yakıt fişkırtılıyordu. Bu ilk saldırıdan sonra yeniden düşman üzerine dönülüp, önce küreklerin kırılması ya da ezilmesi için manevra yapılıyor, hemen sonrasında da düşman gemisi vasatından mahmuzlanıyordu. Bu tür deniz savaşının en son aşamasında ise bordalanan/mahmuzlanan düşman gemisine çıkan denizciler, göğüs gögüse, kılıç ve mızraklarıyla ölesiye savaşıyorlardı ${ }^{8}$.

\footnotetext{
${ }^{6}$ Kadırga, hem kürekle, hem de yelkenle yürütülen ve yönetilen, eski dönemin en etkin savaş gemisidir (Süleyman Nutkî, Kamûs-i Bahrî [Deniz Sözlüğü], Haz.: Mustafa Pultar, Türkiye İş Bankası Kültür Yayını, İstanbul, 2011, s. 140). Kadırga sözcüğü, dilimize,

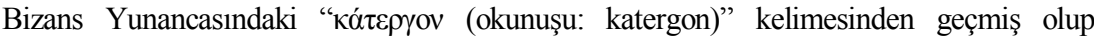
"kadirga", "katırga" ve "kedirga" biçimlerinde de kullanılmıştır; eski Rusçası "katarga", eski Sırpçası ve Bulgarcası "katrıga", Romencesi de "katregu" şeklindedir (Henry \& Renée Kahane ve Andreas Tietze, The Lingua Franca in the Levant, ABC Kitabevi, İstanbul, 1988, ss. 523-526). İngilizcesi ise "galley"dir (René De Kerchove, International Maritime Dictionary, Second Edition, Van Nostrand Reinhold, New York, 1948, s. 322).

${ }^{7}$ Savaş gemilerinin tayfası yalnızca yelkenci, kürekçi ve savaşçılardan oluşmamakta, bu ekibin içerisinde geminin olağan bakımlarını ve gerektiğinde kolay/geçici onarımlarını yapan usta marangozlar da yer almaktaydi.

${ }^{8}$ Craig F. Posey, "Signal Close Action", The General (Magazine), Vol. 25, N. 4,
} 
Ortaçağda dönemin kadırga teknolojisi göz önüne alındığında, 14. yüzyılda tipik bir savaş kadırgasının gün boyunca ortalama hızı iki veya üç knot'1 geçemiyordu. Gece kürekçilerin dinlenmesi hesaba katıldığında bu hız ortalama 1,5 knot'a düşmekteydi. ${ }^{9}$ Seyir süresince karşılaşılan en büyük sorun ise erzak ve su ikmaliydi. Bu yüzden deniz muharebesi kıyıya yakın yerde, müstahkem bir mevkiye dayanılarak icra ediliyordu. ${ }^{10} \mathrm{Bu}$ açmazın temellerinden biri olan kadırgaların hızı hakkında şunlar söylenebilir: Kâtip Çelebi'nin verdiği bilgiye göre, rüzgârın uygun olması halinde 500 mil olan Rodos-İskenderiye arasını, iki gece denizde giderek kat etmek mümkündür. Hava uygun olmazsa, kürekle üç-dört gecede gidilebilmektedir. Nitekim İstanbul'a doğru yola çıkan İskenderiye gemisindeki esir Heberer, hatıralarında İskenderiye-Rodos arasını rüzgârlı havada dört günde, İstanbulİskenderiye arasını ise 12 günde geçtiklerini belirtmektedir. Ancak kötü hava şartlarında bu sürenin 40 güne ulaştığı da oluyordu. ${ }^{11}$

Denizlerde dönemin muharebe/çatışma sistemi, savaş gemilerinin birbirlerine rampa olmasına dayalıydı. Hatta Doğu Roma donanması yanıcı maddeleri bir körük aracılığıyla pruvadan firlatma yeteneğine sahip "syphon" adlı mekanizmayı daha yedinci yüzyılda 677 Sylaeum Savaşı'nda Emevilere karşı Marmara Denizi'nde kullanabilmiş üstün bir teknolojiye de sahipti. ${ }^{12}$

Deniz savaşlarında uzak mesafeden yüksek etkinlik ve savaş üstünlüğü sağlayan top, Avrupa donanmalarında çok erken tarihlerde kullanılmaya başlandı. 1336' da Anvers'e hücum eden savaş gemilerinin bordalarında Tournai'de yapılmış toplar yer alıyordu. Venedik tekneleri

\footnotetext{
Avalon Hill, Baltimore, 1989, s. 19.

9 Emrah Safa Gürkan, "50 Günde Devr-i Bahr-1 Sefid: Königsbergli Lubenau'nun Kadırgayla İmtihanı”, Osmanlı Araştırmaları Dergisi, İstanbul, 2014, s.279.

${ }^{10}$ Gökhan Atmaca ve Doğan Tanrıverdi, Türklerin Tarihinde 30 Büyük Deniz Savaşı, İstanbul, 2016, s. 14.

${ }^{11}$ Katip Çelebi, Tuhfetü'l-kibar fi Esfari'l bihar, İstanbul, 1970, s. 221; Michael Bretten, Osmanlıda Bir Köle, İstanbul, 2016, ss. 151, 162, 185.

${ }^{12}$ Gökhan Atmaca ve Doğan Tanrıverdi, a.g.e., s. 14.
}

\section{1}

Güvenlik Stratejileri

Cilt: 15

Say1: 31 
552

Güvenlik Stratejileri

Cilt: 15

Say1: 31

ise ancak 1380'de toplarla donatılmıştı. İspanyol gemilerinde büyük olasilıkla 1359 ve 1372 'de toplar bulunuyordu ve 1381'de Katalan ticaret gemilerinin bordalarında da toplar mevcuttu. Yıllar boyu denizlerde ateşli silahların kullanılmış olması, rakip gemileri batırmaktan çok düşman denizcileri vurmaya yaramış; yol kesme ve şiddetli çarpışma denizlerdeki mücadelenin olağan teknikleri olarak kalmıştı. ${ }^{13}$

15. yüzyılda toplarla donatılmış "yuvarlak gövdeli gemiler" ise Venedikliler tarafından bir yardımcı gemi ya da denizlerde korsanlara karşı devriye gemisi olarak kullanılmak üzere yapılmıştı. Kadırgalar ve bu yuvarlak gövdeli gemiler, 18. yüzyıl başlangıcına kadar Akdeniz'deki savaş filolarının en önemli gemileri olarak kalmıştı. Bu durum, Venedik için olduğu kadar Cenova, Osmanlı ve Malta donanmaları için de geçerliydi. 15. yüzyılın ortalarına doğru, kadırgalar, kıç kasarasına yerleştirilmiş bir çift topla donatılmıştı. 16. yüzyılın kadırgaları ise farklı büyüklüklerde önemli sayıda top taşıyordu. Pruva ve kıç taraflarındaki iki yüksekçe platform (kasara) farklı ağırlıklarda 15 kadar topun yerleştirilmesine olanak tanıyordu. Kadırganın baş tarafinın tam ortasına yerleştirilmiş 16 libre ağırlı̆̆ındaki iki topla, 69 libre ağırlığında bir top daha vardı. Bu donanım, kadırgalara önemli bir ateş gücü sağlıyordu. Küreklerin yardımıyla hareket edebilen bu tekneler, Akdeniz'in sakin sularında rüzgârın yokluğunda bile ağır ve iri gövdeli yelkenli gemilere başarıyla meydan okuyabiliyordu. ${ }^{14}$

Eldeki kayitlardan, 1488 yılında Osmanlı Donanmasında da bazı gemilerin değişik çapta toplarla donatıldığını öğrenmekteyiz. ${ }^{15}$ Bunların Sultan Bayezıd döneminde yaptırılan ve Kemal ile Burak Reislerin kumanda ettiği Modon ve Koron harekâtlarında kullanılan "göke"ler ${ }^{16}$ olduğu bilinmektedir. Göke aslında yeni tip olarak Osmanlı

${ }^{13}$ M.Carlo Cipolla, Yelken ve Top, İstanbul, 2003, s. 38.

${ }^{14}$ M.Carlo Cipolla, a.g.e., s .40.

${ }^{15}$ Salim Aydüz, Tophâne-i Âmire ve Top Döküm Teknolojisi, Türk Tarih Kurumu Yayın1, Ankara, 2006, s. 467.

${ }^{16}$ Kürekli ve yelkenli çektiri sınıfı olup altı mavna üstü kalyon şeklinde tasarlanmıştır. 
donanma envanterine girerken, Avrupa gemilerinde topların görülmeye başlaması bir dizi yeniliği de beraberinde getirmişti. Bunun ilki, Akdeniz ve kuzey denizciliği arasındaki ilişkilerin sıkılaşması; gemilerde iki yan dümenin yerini arkada tek bir dümenin alması ve Kuzey Avrupa denizlerinde sıkça görülen Kogge'un taklidi olan cocca'ların Akdeniz'de boy göstermesiydi. Kogge, büyük kare yelkenle donatılmış bir ana direkle bir arka direğe sahipti; daha küçük ana direğe sahip cocca ise Latin yelkeniyle donatılmıştı. Kıç tarafinda tek dümen kullanmanın yaygınlaşması, gemilerin tonajlarını arttırmalarına ve açık denizde ulaşımın sağlanmasına olanak tanıyarak manevra yetenekleri ve hızlarını mükemmelleştirmiş olmalıydı. Denizciliğin gelişmesini sağlayan diğer yenilikler ise pusulanın kullanımı ve Atlantik bölgesinde açık denizlerdeki ulaşımın ilerlemesi, denizcilik haritalarının yaygınlaşması, Akdeniz'de haritacılık biliminin doğuşu ve gelişimi, kitlelerin hayat koşullarındaki iyileşme ve 15 . yüzy1l boyunca ticaretin genişlemesiydi. ${ }^{17}$

$\mathrm{Bu}$ yıllarda, artık topun kullanımındaki tek sorun, barutun, deniz ortamında çabuk nemlenmesi ve etkinliğinin hızla düşmesiydi. 1512 yılında top, ilk kez, Brest'de, İngiliz ve Fransız donanmaları arasındaki deniz savaşında, asıl silah olarak ve yoğun biçimde kullanıldı. Böylece, düşmanla denizde göğüs gögüse savaşmak yerine artık göreceli güvenli bir uzaklıktan ve eskiye göre daha ölümcül sonuç alacak biçimde savaşmak olanaklı olmuştu.

Kürekle yürütülen savaş gemilerinden yelken çağı gemilerine ve daha sonra günümüz pervaneli savaş gemilerine kadar süren teknik (gemi inşa) alandaki gelişmeler, gemilerin savaşma biçimlerini de etkilemiştir. Savaş gemilerinin yapım ve donatımındaki değişimleri ve dolayısıyla deniz savaşı yöntemlerini de etkileyen bu tarihsel süreç,

Seren yüksekliği 53 metre, tekne yüksekliği ise 15 metre olan gökelerin üç güvertesi bulunur. Alt katta her biri dokuz kürekçi tarafindan çekilen 25 çift kürek bulunmaktadır. Kıç tarafına ise iki büyük kayık yerleştirilmiştir. Ağır toplarla donatılan gökelerin en büyük sorunu manevra yeteneği olmuştur.

${ }^{17}$ M.Carlo Cipolla, a.g.e., s. 39. 
554

Güvenlik Stratejileri

Cilt: 15

Sayı: 31

amiraller ve kaptanlar arasındaki iletişimin önemini daha da arttırmış, etkini hızlı ve güvenilir çözüm için yeni arayışların başlatılmasına neden olmuştur.

\section{Deniz Savaşlarına Yönelik Taktik Emirlerin Yayınlanması}

Ülkelerin politikaları ve deniz çıkarlarına yönelik stratejileri doğrultusunda tasarlanan ve geniş bir coğrafyayı kapsayan deniz gücünün (donanma ve/veya filoların) konuşlandırılması, tarihin her döneminde aynı önemi korumuştur. Etkin donanma yönetimiyle ilintili olarak söz konusu konuşlanmanın gereği olan emir-komuta bağlantısı, içinde bulunan zamanın iletişim teknolojisine bağlı şekilde biçimlenebilmiştir. Orta Çağ'da uzak mesafeli iletişim söz konusu olmadığından, farklı bölgelerde konuşlandırılan filoların komutanları, çoğu zaman taktik uygulamalar bakımından bağımsız yöneticiler olarak görev yapmış, bazen de aldıkları emirlerin gereği olarak bir araya gelip (sıklet merkezi oluşturup) güçlü bir donanma kuruluşu içerisinde deniz savaşına katılmıştır. ${ }^{18}$ Bu nedenle, filo veya donanma komutanları, uygulamayı tasarladıkları manevra ve savaş taktiklerini, emirlerindeki gemilere en etkin bir yöntemle (genellikle kısaltılmış bilgi-kod şeklinde) iletebilmek amacıyla, gündüz ve gece uygulamaları farklı olan iletişim yöntemleri üretmiş ve bunları uzun süreli geçerliliği olan yazılı emirler biçiminde yayınlamıştır.

Deniz savaşları sırasında emirlerin iletilmesi bağlamındaki ilk uygulama örneği, Herodot tarafından belirtildiğine göre (büyük bir olasılıkla), Pers kralı I. Serhas'ın M.Ö. 480 yılında, Yunanistan'ın fethi seferi amacıyla Makedonya'nın Therma kentinden ayrılmak üzere bir Fenike gemisine binerken "filonun tüm gemilerine seyre başlamaları için işaret verin" şeklindeki emridir. ${ }^{19}$ Burada kullanılan "seyre

${ }^{18}$ Hüseyin Serdar Tabakoğlu. "Commanding the Sea: The Spanish Naval High Command in the Early Modern Mediterranean", Cihannüma: Tarih ve Coğrafya Araştırmaları Dergisi, Sayı: II/1, 2016, s. 5-6.

${ }^{19}$ William Gordon Perrin, "British Flags, Their Early History and Their Development at Sea: With an Account of the Origin of the Flag as a National Device", Cambridge 
başlama işareti" terimiyle ilgili ilginç husus, Latince "signum"

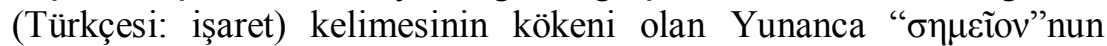
(okunuşu: simiyon), hemen hemen tüm Latince kaynaklı yabancı dillerde "semeion (tekil) / semeia (çoğul)" = "başlama/başlangıç işaret(ler)i” olarak tanımlanmış ${ }^{20}$ olmasıdır.

Gemiler arasındaki iletişimle ilgili bilinen en eski yöntem, seslenmek olmuştur. Benzer biçimde boru, düdük veya davul gibi ses çıkaran araçlarla, hatta güllesiz (kurusıkı) top atışlarıyla da iletişim sağlandığı bilinmektedir. Ancak sesle yapılan iletişimin, fırtınalı havada veya bir deniz savaşı sırasında yetersiz, hatta olanaksız olduğu aşikârdır. 16. ve 17. yüzyıllarda, birçoğu Avrupa kökenli olan denizcilerin özel bayrak ve flamalarla yapılan haberleşmeyi bildikleri ve kullandıkları, gece karanlığında ise fenerlerden yararlanarak haberleştikleri değerlendirilmektedir. Bu dönemde bayrak, flama ve fener kullanarak yapılan iletişim yöntemi yalnızca bilgi iletmek amacıyla değil; gemilerin birbirlerini izlemeleri ve savaş konuşlanmasındaki mevkilerini korumaları için de önemli bir uygulamaydı. ${ }^{21}$ Bayrak ve flamalar, bir emri veya bilgiyi açıklamak için tek başlarına kullanılabildikleri gibi ${ }^{22}$ birden çok sayıda kullanılarak ya da farklı yerlere/direklere ${ }^{23}$ çekilerek değişik anlamlar oluşturabiliyorlardı. Benzer uygulama fenerler için de söylenebilirdi.

Deniz savaşlarılyla ilgili bu gelişmeler, gemilerin ve savaş araçlarının kullanımına yönelik temel kuralların (taktiklerin)

University Press Archive, Cambridge, İngiltere, 1922, s. 140.

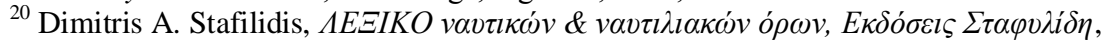
Atina, Yunanistan, 2008, s. 1253.

${ }^{21}$ Emrah Safa Gürkan, Sultanın Korsanları: Osmanlı Akdenizi’nde Gazâ, Yağma ve Esaret 1500-1700, Kronik, İstanbul, 2018. s.347.

22 Örneğin tek başına beyaz bayrak, barışçıl niyeti ve müzakare isteğini belirtirken; kırmızı bayrak, savaş anlamını taşırdı. Bu bağlamda ulusal bayrağın da tek başına dalgalandırılmasının farklı bir mesaj ilettiği bilinmektedir.

${ }^{23}$ Aynı bayrak/flama ve bayrak/flama grubunun, pruva direğine çekilmesi durumunda taşıdığı anlam, grandi direğine çekilmesiyle aynı değildir. Benzer uygulama, fenerlerin gemide gösterildikleri yerle ilintili olarak farklı anlam taşıdıkları bilinmektedir. 
556

Güvenlik

Stratejileri

Cilt: 15

Sayı: 31

belirlenmesini ve bu hususlara yönelik emirlerin önceden yayınlanmasını gerektiriyordu. Bugüne değin araştırılmış/bilinen arşiv bilgileri ışığında, Kaptan James Dolfin tarafindan 9 Eylül 1365 tarihinde Venedik filosu için yayınlanmış olan ve Türkçesi bu çalışmada Ek olarak sunulan savaş talimatının, ${ }^{24}$ bu konuda bir "ilk" ve günümüzdeki uygulamaların da atası olduğu değerlendirilmektedir.

Osmanlı deniz tarihinde ise bunun tam benzeri olamamakla birlikte, Sultan Abdülmecid döneminde hazırlanan 1849 tarihli Bahriye Nizamnâmesi'nin 1şı̆̆ında, kaptan paşaların kendilerine özgü savaş taktikleri ile denizde uygulanmasını düşündükleri manevralara yönelik görüşlerini kapsayan emirnameler yayınladıkları değerlendirilmektedir. Bugüne kadar, arşivlerimizde böyle bir kaynağa henüz ulaşılmamasına karşın, Deniz Kuvvetleri Komutanlığı tarafindan 1994 yılında çevirisi yayınlanan eski bir Görünür Muhabere $\mathrm{Kod} \mathrm{Kitabl}^{25}$ bu görüşümüzü desteklemektedir.

\section{Sonuç}

Askerî konularda yayınlanmış tüm yazılı belgelerde özellikle belirttildiği gibi "önce muhabere, sonra muharebe" özdeyişinden hareketle, bir deniz savaşında (veya tatbikatında/manevrasında) başarı etkin, hızlı ve güvenilir iletişimle sağlanır. Bu iletişimin temelini, diğer bir deyişle, bu uygulamaya yönelik ihtiyacı da deniz savaş taktikleri oluşturmaktadır. Dolayısıyla, denizde görev yapan bir savaş gücünü yönetecek amiralin uygulamayı tasarladığı bir deniz harekâtının öncesinde, bilgi ve deneyimleri işı̆̆ında hazırlayıp yayınlayacağı kısa, anlaşılır ve uygulanabilir (uygulama kabiliyeti olan) direktiflerini, etkin, hızlı ve güvenilir bir iletişim ortamı sağlayarak yayınlaması, kesin başarının elde edilmesine katkı sağlayacaktır.

${ }^{24}$ David S.T. Blackmore, Warfare on the Mediterranean in the Age of Sail: A History 1571-1866, McFarland, North Carolina, 2011, s. 38.

25 “Osmanlı Bahriyesi Görünür Muhabere Kod Kitabı", Hazırlayanlar: İskender Pala, Nurcan Bal, Sey.Hid.Oşi.D.Bşk.lığı, İstanbul, 1994. 
Söz konusu iletişimde sağlanması gereken etkinlik, hız ve güvenilirlik, önceden belirlenmiş taktiklerin en kısa ve en anlaşılabilir biçimde "kod"lanmasıyla elde edilebilir.

Dolayısıyla, günümüzde yaygın biçimde uygulanmakta olan bu düzenlemelerin, tarihteki ilk yazılı örneğinin günümüz Türkçesine çevirisi ve tanıtımı olan çalışma, gelecekte yapılacak yeni araştırmalar için de temel teşkil edecektir.

\section{Summary}

The seas have been used brutally as a battlefield in order to protect the national interests of the countries and to meet their demands for expansion. For this reason, when talking about "Naval History", the first thing that comes to mind is battle. It is necessary to have previously designed movements and communication tools and methods to explain these movements in order to be able to deploy, orient, and respond to movements of enemies in changing conditions. Therefore, effective, fast, and reliable communication in a battle or conflict provides a great contribution to the victory. The basis of the communication utilized in naval battles determines the tactics to be used. An Admiral commandeering a combat force at sea requires communication without entering into too much detail, but with giving the general orders for the deployment of the unit in question and applying the most appropriate combat scheme to the situation, commanding the tactics to be used and reporting the tactical picture of the developing situation. In this context, prior to a naval war, it is necessary to determine the basic rules (tactics) for the use of ships and other combat vehicles, and to pre-publish orders for these issues.

Technological developments (in shipbuilding), which lasted from rowing warships to sailing ages and to modern day's selfpropelled warships, influenced also the ways in which ships battles. This historical process, which affected also the changes in the construction and equipment of warships and thus the naval war 
558

Güvenlik Stratejileri

Cilt: 15

Say1: 31

methods, increased the importance of communication between the admirals and the captains, and thus new searches were initiated for effective solution.

Within the scope of this study, the directive prepared in Latin by Captain James Dolfin for a Venetian Fleet of four galleries in Cyprus has been presented in Turkish. This directive is the first and only written document that is known as of today. This document is similar to the instructions published in the Ottoman Navy in later years.

Considering the maritime language used in the content of this directive, it is also important that the translations (from Latin into Italian and into English languages) were made by naval officers. This study was carried out with the aim of presenting historical information to tacticians and planners in Turkish Navy.

\section{KAYNAKÇA \\ Kitaplar}

ATMACA, Gökhan ve TANRIVERDİ Doğan, Türklerin Tarihinde 30 Büyük Deniz Savaşı, İstanbul, 2016.

AYDÜZ, Salim, Tophâne-i Âmire ve Top Döküm Teknolojisi, Türk Tarih Kurumu Yayın1, Ankara, 2006.

BLACKMORE, David S.T., Warfare on the Mediterranean in the Age of Sail: A History 1571-1866, McFarland, North Carolina, 2011.

BRETTEN, Michael, Osmanlıda Bir Köle, İstanbul, 2016.

CIPOLLA, M.Carlo, Yelken ve Top, İstanbul, 2003.

De KERCHOVE, René, International Maritime Dictionary, Second Edition, Van Nostrand Reinhold, New York, 1948.

GÜRKAN, Emrah Sefa, Sultanın Korsanları: Osmanlı Akdenizi'nde Gazâ, Yağma ve Esaret 1500-1700, 2. Bask1, Kronik Kitap, İstanbul, 2018.

KAHANE, Henry \& Renée ve TIETZE Andreas, The Lingua Franca in The Levant, ABC Kitabevi, İstanbul, 1988.

KATİ ÇELEBİ, Tuhfetü'l-kibar fi Esfari'l bihar, İstanbul, 1970.

NUTKÎ, Süleyman, Kamûs-i Bahrî (Deniz Sözlüğ̈̈), Haz.: Mustafa Pultar, Türkiye İş Bankası Kültür Yayını, İstanbul, 2011. 
Deniz Taktik İşaretlerinin Yazılı İlk Kaynağı

PALA, İskender ve BAL, Nurcan (Hazırlayanlar), Osmanlı Bahriyesi Görünür Muhabere Kod Kitabl, Sey.Hid.Oşi.D.Bşk.lığı, İstanbul, 1994.

PERRIN, William Gordon, British Flags, Their Early History and Their Development at Sea; With an Account of the Origin of the Flag as a National Device, Cambridge University Press Archive, Cambridge, İngiltere, 1922.

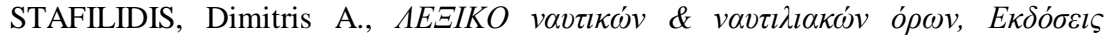
$\Sigma \tau \alpha \varphi v \lambda i \delta \eta$, Atina, Yunanistan, 2008.

UZUNÇARŞILI, İsmail Hakkı, Osmanlı Devleti'nin Merkez ve Bahriye Teşkilatı, Türk Tarih Kurumu Yayınları, Ankara, 1988.

Makaleler ve Kitap Bölümleri

BOSTAN, İdris, "Mezemorta Hüseyin Paşa ve 1701 Tarihli Bahriye Kanunnamesi", Türk Denizcilik Tarihi, Deniz Basımevi Müdürlüğü, İstanbul, 2009.

GÜRKAN, Emrah Sefa, "50 Günde Devr-i Bahr-1 Sefid: Königsbergli Lubenau'nun Kadırgayla İmtihanı", Osmanlı Araştırmaları Dergisi (The Journal of Ottoman Studies), Sayı: XLIII, İstanbul, 2014.

POSEY, Craig F., "Signal Close Action", The General (Magazine), Vol. 25, N. 4, Avalon Hill, Baltimore, 1989.

TABAKOĞLU, Hüseyin Serdar, "Commanding the Sea: The Spanish Naval High Command in the Early Mediterranean", Cihannüma: Tarih ve Coğrafya Araştırmaları Dergisi, Sayı: II/1, 2016. 


\section{KAPTAN JAMES DOLFIN TARAFINDAN YAYINLANAN DENIZ TARIHIINDEKİ İLK YAZILI DIREKTIF}

EK

Tanrı, Meryem Ana ve Evanjelist yol göstericimiz Aziz Markos ${ }^{26}$ ile tüm Azizler adına EMIRLER

Kıbrıs istasyonunda bulunan dört kadırganın kaptanı soylu Bay James Dolfin tarafindan verilmiştir.

Ilk Olarak - Kaptanın emir ve komutalarının uygulanması sırasında, hiç kimse Tanrımıza, onun Kutsal Annesine veya erkek ya da kadın olsun herhangi bir Azize, sözle veya eylemle hakaret etme cüretini gösteremez, böyle bir durum ortaya çıkarsa Kaptan, bu suçu işleyen kişiyi cezalandıracak, ancak verilecek ceza çok şiddetli (ölümcül) olmayacaktır.

Kadırgalar, bir arada bulunduklarında; Bay Nicholas Bembo, Kaptanın sancağında, Bay Bernard Balbi, Kaptanın iskelesinde ve Bay Francis Corner de onun (Bernard Balbi'nin) iskelesinde konuşlanacaklardır. Aksi emredilmedikçe, seyir halindeyken de bu mevkiler (borda nizamında, kemere yönünde) korunacaktır; uygulanmamas1 durumunda cezas 100 soldi $^{27}$, dir.

Madde - Hiçbir kadırga, Kaptanın kadırgasının ilerisine (önüne) geçemez, her seferinde cezası 20 soldi'dir.

Madde - Hiçbir kadırga, bir diğer kadırganın pruvasından geçemez, cezası aynıdır (20 soldi).

Madde - Eğer Kaptan bir hız ölçümü yapmak isterse (örneğin; seyir hızını belirlemek/değerlendirmek gibi), başüstüne, gönderli bir gidon yerleştirecektir. Tüm kadırgalar da aynı işlemi yapacaklar (başüstüne, gönderli bir gidon yerleştirecekler), birbirlerine herhangi bir tehlike/zarar oluşturmaksızın, hız bakımından üstünlük sağlamaya çalışacak biçimde (yüksek hızla) seyredeceklerdir.

Madde - Kaptan, filoyu borda nizamında savaş düzenine almak isterse, bu durumda, çanaklığa (geminin en yüksek yerine), pruva yönüne doğru, yani Aziz Markos'lu "standard" sancağ ${ }^{28}$ (Venedik Bayrağı) yönünde, eğilip (yere paralel biçimde)

${ }^{26} \mathrm{~Hz}$. İsa'nın havarisi Aziz Petrus'un verdiği bilgiler doğrultusunda en eski İncil'i yazmış ve Venedik kentinin koruyucusu olduğu kabul edilen kutsal kişi.

${ }^{27}$ Venedik gümüş lirası.

${ }^{28}$ Aziz Markos'un görüntüsünü içeren ilk Venedik bayrağı, 1177 yılında kullanılmaya 
yatırılmış olarak gönderli bir gidon yerleştirecektir.

Ve eğer filoyu pruva nizamında savaş düzenine almak isterse, bu (çanaklıkta, standard Venedik sancağ̀ yönündeki) gönderli gidonu dik duruma getirecektir. Bu uygulamanın her ihlalinde ceza 40 soldi'dir.

Madde - Hiçbir kadırga, Kaptan'ın bulunduğu kadırgada bir tente uygulaması yapılmadıkça, tentesini açamaz veya açılmış tentesini kapatıp saramaz. Böyle bir ihlalin görüldüğü her seferinde ceza, 20 soldi'dir.

Madde - Hiçbir kadırga, Kaptan'ın bulunduğu kadırgada benzer bir uygulama yapılmadan önce, botunu denize indiremez veya borda iskelesini veremez. Bu suç, her seferinde 100 soldi ile cezalandirılacaktır.

\section{GÜNDÜZ, YELKENLE SEYİR HALINDE}

Madde - Kaptan yelken seyri niyetinde olursa, tüm kadırgalar kürek çekmeyi durduracak ve daha fazla ileri çıkmaktan sakınacaklar, bir çatışma veya kazaya neden olmayacak kadar birbirlerinden açı bulunacaklar ve Kaptanın rüzgâraltına konumlanacak biçimde mevki alacaklardır, yanlış uygulama ve hata durumunda ceza 100 soldi'dir.

Madde - Hiçbir kadırga bir diğerinin rüzgârını kapatamaz/engelleyemez, cezası 100 soldi'dir.

Madde - Gündüzleyin yelkenle seyir halindeyken, Kaptan bir karar toplantısı veya oylaması yapmak isterse, kadırgasına büyük bir bayrak çekecek; bu durumda tüm kadırgalar, ustalıkla manevra yaparak Kaptanın kadırgasına yaklaşacak ve her biri her an göreve hazır olduğunu görüntüleyecektir. Eğer geceleyin Kaptan, kadırgaların durumunu denetlemek isterse, kadırgasının çanaklığında (en yüksek yerinde) bir ışı̆̆ı, sabit olarak söndürmeden yakacaktır; bu durumda bütün kadırgalar, Kaptanın kadırgası bu mevkiini koruduğu sürece, kıç üstlerinde birer 1şık yakacaklardır.

\section{GECE, DENIZDE}

Madde - Eğer Kaptan mizana yelkeniyle gece seyri yapmak isterse, kadırgasının vasatında, yanyana iki 1şı gösterecektir.

Eğer trinketa yelkenini açmak isterse, kadırgasının vasatında, yan yana üç ışık gösterecektir. Eğer babafingo yelkenini açmak isterse, aynı şekilde konumlandırılmış (kadırgasının vasatında, yan yana) dört 1şık gösterecektir.

Eğer firtına yelkenini açmak isterse, benzer biçimde konumlandırılmış (kadırgasının vasatında, yan yana) beş ışı gösterecektir.

başlanmıştır. XIV. yüzyılda ise, beyaz zemin üzerinde, Aziz Markos'un yüzünü taşıyan kırmızı renkte bir aslan görüntüsüyle değişmiştir. Savaş kadırgalarında kullanılan bayrak, kırmızı zemin üzerinde altın yaldızla işlenmiş aslan görüntüsünü içerir ve uçum bölümü saçaklıdır. 


\section{Derya Şerif YARKIN - Gökhan ATMACA}

562

Güvenlik

Stratejileri

Cilt: 15

Say1: 31

Madde - Rüzgâr arttığında, eğer Kaptan bu durumda yukarıda belirtilen yelkenlerden herhangi birini istinga veya saravele etmek isterse, kadırgasının vasatında, yan yana altı 1şık gösterecek ve diğer her kadırga aynı işaretle buna yanıt verecektir.

Madde - Eğer Kaptan, yukarıda belirtilen yelkenlerden herhangi ikisini istinga veya saravele etmek isterse, kadırgasının vasatında, alt alta iki ışık gösterecektir.

Ve eğer Kaptan yelken kullanmaksızın seyir yapmak isterse, yelkeni istinga veya saravele etmek için yukarıda belirtilen 1şık işaretini gösterdikten sonra, kadırgasının çanaklığının hemen altında bir ışık yakacak ve bu 1şığı, yelkensiz seyir yapma isteği süresince yanar durumda tutacaktır. Tüm kadırgalar, bu süre zarfında, kıçüstlerinde bir 1şık yakacaklar ve Kaptan, 1şığını söndürdüğü anda onlar da söndüreceklerdir, gözlemlenen hatanın cezası 100 soldi'dir.

Madde - Eğer geceleyin, kadırgalardan biri büyük bir kazaya uğrarsa (Tanrı korusun!), o kadırga ne kadar ışığı varsa hepsini yakacak, diğer kadırgalar, en hızlı bir biçimde onun yardımına koşacaklardır. Ve eğer bu kaza gündüzleyin olursa, kazaya uğrayan kadırga, bandırasını veya Kaptanının tanıtım işaretini ${ }^{29}$ toka edecek ve diğer kadırgalar da ona yardıma gideceklerdir.

Madde - Hiçbir kadırga bir diğeri ile borda bordaya sürtünemez/çatıșamaz, cezası 100 soldi'dir. Ve eğer böyle bir çatıșma sonucunda bir hasar oluşursa, neden olan kadırga, bunu giderecektir. Kazanın oluşumuyla ilgili olumsuzluklar Kaptan tarafından yargılanarak, cezalandırılacaktır.

Madde - Eğer herhangi biri vardiyasında ve gözcülük görevi sırada bir hata/eksiklik yaparsa, yaptığ her hata/eksiklik için 3 grisso $^{30}$ ceza ödeyecektir.

Madde - Üst düzey kişilere ait bile olsa kaybedilmesi durumunda ceza uygulanacağından, ne kadırgaların mürettebatından biri, ne de herhangi bir asker, ister ana vatan topraklarında isterse başka bir yerde olsun sahilde silah taşımaya kalkışmamalıdır, kaybedilmesi durumunda ceza, her kılıç için 15 lire ve her bıçak için 3 liredir.

Burada söz konusu olan silahların, kişilerin kendi özel silahları olduğu dikkate alınmalıdır.

Madde - Fıçı kaybı cezayı gerektirdiğinden, hiç kimse, denetlenmemiş şarap satamaz ve denetlendikten sonra da bu şaraba su katamaz, böyle bir olumsuzluğun öğrenilmesi/belirlenmesi durumunda el koyulan şarap, içmeleri için tayfaya verilebilir.

\section{KUMAR}

Madde - Kaptan, ne para ya da başka birşeyin bir bahis karşılığı olarak ödemede kullanılmasını, ne de bu iş için bir başkasından borç alınıp verilmesini istemez; ayrıca

${ }^{29}$ Her Venedik kadırgası, Venedik'e özgü Aziz Markos'lu "standart” bayrağının yanı sıra, kaptanının rütbesine uygun ayrıca bir tanıtım işareti/bayrağı da çeker.

${ }^{30}$ Toskana kuruşu. 
bu amaçla rehin alınıp, bahis işlemi sonunda geri verilmesini de men edebilir.

Benzer biçimde, herkes, kumar veya bahis yoluyla kazanılan giyim-kuşam malzemelerini, kaybedenlere geri vermekle yükümlüdür ve bu, herhangi bir ceza alma korkusu olmadan, güvenle talep edilebilir.

\section{GÜNDÜZ, KÜREKLE SEYİR}

Madde - Eğer firtına veya başka bir nedenden dolayı kadırgalar, birbirlerini gözden kaybederlerse ya da önce birbirlerini göremeyecek kadar birbirlerinden ayrilıp sonra kadırgalardan bazıları yeniden görüş mesafesine girerlerse, kürekle seyrederken, hangi taraf sayıca fazlaysa, aralarından birini ileri yöne göndermelidir, böylece ileri çıkıp karşı yönde konumlanan kadırga kıç tarafında bayrak toka edecek, diğerleri ise baş taraflarında bayrak toka edeceklerdir.

Daha az sayıda olan taraf, biri sancakta diğeri iskelede olacak biçimde vasatında iki bayrak toka edecek, daha sonra pupa pupaya yaklaşıp seslenme mesafesine girerek birbirlerini tanıyacaklardır. Ve her iki taraf da eşit sayıda kadırgadan oluşuyorsa, birbirlerini benzer işaretleri göstererek tanıyacaklardır.

Madde - Eğer, birbirlerini gözden kaybettikten uzun süre sonra seyir sırasında yeniden göz teması sağlarlarsa, kadırgaların her biri, çanaklığın üzerine bir bayrak toka edecek ve baş tarafa da iki bayrak konumlandıracak, daha sonra çanaklık üzerindeki bayrağı arya edecektir.

$\mathrm{Bu}$ işaretler yardımıyla, birbirlerinin dost olduklarını anlayacaklardır.

Madde - Eğer bu olumsuzluk gece ortaya çıkarsa, önce biri, vasatında, birbirinin üzerinde konumlandırılmış üç 1şık göstererek işaret verecek ve diğeri, aynı biçim ve yerde yerleştirilmiş dört 1şı̂k gösterecektir.

Bundan sonra, üç 1şık gösteren kadırga, 1şıklardan birini kıç tarafa, diğerini baş tarafa taşıyacak ve üçüncüsünü de vasatta koruyacaktır; dört 1şı gösteren kadırga ise, 1şıklardan ikisini baş tarafa, ikisini de kıç tarafa taşıyacaktır.

Ve böylece, birbirlerini dost olarak tanıyacaklardır.

Ancak, kendilerinin şüpheli bir konumda olduklarını değerlendirmeleri durumunda, herhangi bir 1şı göstermeleri zorunlu değildir.

\section{DÜŞMAN KARŞISINDA}

Kaptan, bir düşman kadırgasını veya silahlı gemiyi kovalayıp avlamak isterse, kadırgasının başüstünde, bir gönder üzerinde kendi tanıtım işaretini gösterecektir.

Bu durumda tüm kadırgalar, kovalanıp avlanması istenen düşman kadırgasına veya kadırgalarına ya da silahlı gemiye karşı konuşlanmak üzere, (komuta ederek) uygulayabilecekleri fakat bu konuda daha önce verilmiş emirleri ihlal etmeksizin en yüksek hızla ilerleyecekler ve kadırgaların her biri (bağımsız olarak) düşmana yetişebilir ve onu ele geçirebilirler, bu harekât olanaklar elverdiğince en az hasarla gerçekleştirilecek, Kaptan çatışma mevkiine ulaşıncaya kadar, esirlere ve ganimete zarar verilmeden ele geçirme eylemi gerçekleştirilmiş olacaktır. 


\section{Derya Şerif YARKIN - Gökhan ATMACA}

564

Güvenlik

Stratejileri

Cilt: 15

Say1: 31
Madde - Kaptan, düşman kadırgalarını kovalamayı kesmek (durdurmak) istediğinde, kadırgasının bașüstünde gösterdiği kendi tanıtım ișaretini arya edecek; bu durumda bütün kadırgalar kovalama eylemini kesip kendi mevkilerine döneceklerdir. $\mathrm{Bu}$ husus, Kaptanın, olayın gelişmesiyle ilgili nedenler-sonuçlar hakkında yapacağı değerlendirmeye göre, maddi ve kişisel cezalandırma bağlamında dikkate alınacaktır.

Madde - Eğer Kaptan, icra edilmekte olan harekâta katılmak isterse, kadırgasının kıçüstünde, sancak tarafa, kendi tanıtım işaretiyle birlikte bayrak toka edecek; bu durumda her kadırga, kendisine tahsisli mevkiini alacak ve ilk boru (trompet) sesini duyduğunda, kendine özgü silahlarını kullanmaya (savaşmaya) hazır olacaktır. İkinci boru sesinde, herkes silahlarını kuşanacak ve savaşa hazır olacaktır. Üçüncü boru sesinde, her kadırga ya Kaptanı izleyip tüm gayretiyle savaşacak ya da emredildiği üzere sabit ve sağlam bir şekilde bekleyip düşmanı karşılamaya hazır olacak veya çatışmayı kesintisiz sürdürecek ve savaş bitinceye kadar tüm gayretiyle savaşacaktır; bu husus, emirlere karşı gelen ve etkin savaşmayı ihlal edenin başındaki kişinin cezalandırılması bağlamında gözlemlenecektir.

Madde - Hiç kimse çatışma/dövüşs sırasında ne kaçmak için denize atlamaya, ne de yağmaya kalkışmaya cesaret edemez, cezası ölümdür.

Madde - Eğer kovalama veya savaşma sonucunda herhangi bir düşman kadırgası veya düşman gemisi ele geçirilmişse, hiç kimse, hiçbir şeyi yağmalamaya kalkışamaz; bu husus, Kaptanın, olayın gelişmesiyle ilgili nedenler-sonuçlar hakkında yapacağı değerlendirmeye göre, maddi ve kişisel olarak cezalandırılabilir ve hiç kimse çaldığ 1 bir şeyi saklayamaz. Benzer şekilde, esir alınmış kişiye karşı suç işlemek yasaktır.

Madde - Kaptan, kendisi tarafindan belirlenmiş ve yukarıda belirtilen tüm emirlerin, uygulamaya yönelik koşullara bağlı olarak çok veya az oranda verilebilecek cezalarıyla birlikte göz önünde bulundurulmasını ister ve emreder. 